\title{
A receptor-like protein acts as a specificity switch for the regulation of stomatal development
}

\author{
Guangzhong Lin, ${ }^{1,2}$ Liang Zhang, ${ }^{3}$ Zhifu Han, ${ }^{1}$ Xinru Yang, ${ }^{1}$ Weijia Liu, ${ }^{1}$ Ertong Li, ${ }^{4}$ Junbiao Chang, ${ }^{5}$ \\ Yijun Qi, ${ }^{6}$ Elena D. Shpak, ${ }^{3}$ and Jijie Chai ${ }^{1,6,7,8}$ \\ ${ }^{1}$ Innovation Center for Structural Biology, Tsinghua-Peking Joint Center for Life Sciences, School of Life Sciences, Tsinghua \\ University, Beijing 100084, China; ${ }^{2}$ College of Life Sciences, Peking University, Beijing 100871, China; ${ }^{3}$ Biochemistry, Cellular, \\ and Molecular Biology, University of Tennessee, Knoxville, Tennessee 37996, USA; ${ }^{4}$ College of Chemistry and Molecular \\ Engineering, Zhengzhou University, Zhengzhou 450001, China; ${ }^{5}$ Collaborative Innovation Center of New Drug Research and \\ Safety Evaluation, Zhengzhou University, Zhengzhou 450001, China; ${ }^{6}$ Center for Plant Biology, School of Life Sciences, Tsinghua \\ University, Beijing 100084, China; ${ }^{7}$ Max-Planck Institute for Plant Breeding Research, 50829 Cologne, Germany; ${ }^{8}$ Institute of \\ Biochemistry, University of Cologne, 50674 Koeln, Germany
}

Stomata are microscopic openings that allow for the exchange of gases between plants and the environment. In Arabidopsis, stomatal patterning is specified by the ERECTA family (ERf) receptor kinases (RKs), the receptor-like protein (RLP) TOO MANY MOUTHS (TMM), and EPIDERMAL PATTERNING FACTOR (EPF) peptides. Here we show that TMM and ER or ER-LIKE1 (ERL1) form constitutive complexes, which recognize EPF1 and EPF2, but the single ERfs do not. TMM interaction with ERL1 creates a binding pocket for recognition of EPF1 and EPF2, indicating that the constitutive TMM-ERf complexes function as the receptors of EPF1 and EPF2. EPFL9 competes with EPF1 and EPF2 for binding to the ERf-TMM complex. EPFL4 and EPFL6, however, are recognized by the single ERfs without the requirement of TMM. In contrast to EPF1,2, the interaction of EPFL4,6 with an ERf is greatly reduced in the presence of TMM. Taken together, our data demonstrate that TMM dictates the specificity of ERfs for the perception of different EPFs, thus functioning as a specificity switch for the regulation of the activities of ERfs.

[Keywords: biochemical interaction; peptide hormones; receptor kinases; receptor-like protein; stomatal development; structure]

Supplemental material is available for this article.

Received February 15, 2017; revised version accepted April 28, 2017.

In animals, cell-cell communication via peptide hormones is crucial for development and tissue patterning (MacDonald et al. 2009). Similarly, plants also rely on numerous secreted peptide signals to coordinate growth and development (De Smet et al. 2009; Motomitsu et al. 2015). The signaling pathways enabling cell-cell communications often can generate distinct responses in different tissues. This can be exemplified by the ERECTA family (ERf) signaling pathway in Arabidopsis that regulates different developmental processes in the epidermis and vasculature.

In the epidermis, the ERf signaling pathway regulates the development of stomata, which are microscopic pores ubiquitously used by land plants for gas exchange. Several secreted peptides from the EPIDERMAL PATTERNING FACTOR (EPF) family, LRR receptor kinases (LRR-RKs) from the ERf (ER, ER-LIKE1 [ERL1], and ERL2), and the

Corresponding author: chaijj@tsinghua.edu.cn

Article published online ahead of print. Article and publication date are online at http://www.genesdev.org/cgi/doi/10.1101/gad.297580.117.
LRR receptor-like protein (LRR-RLP) TOO MANY MOUTHS (TMM) enforce stomatal patterning (Nadeau and Sack 2002; Shpak et al. 2005; Hara et al. 2007, 2009; Hunt and Gray 2009; Abrash and Bergmann 2010; Hunt et al. 2010; Kondo et al. 2010; Sugano et al. 2010; Abrash et al. 2011; Lee et al. 2012). The EPF family consists of 11 cysteine-rich peptides, with EPF1,2 and EPFL2,4,5,6,9 having been shown to interact with ERf receptors in Arabidopsis (Abrash et al. 2011; Lee et al. 2012, 2015; Uchida et al. 2012; Tameshige et al. 2016). Three peptides-EPF1, EPF2, and EPFL9 (STOMAGEN)-regulate stomata development (Supplemental Fig. S1). EPF2 is expressed during early epidermis development and is perceived primarily by ER to restrict the initiation of stomatal cell lineages, while EPF1 is expressed later than EPF2 and is perceived

(C) 2017 Lin et al. This article is distributed exclusively by Cold Spring Harbor Laboratory Press for the first six months after the full-issue publication date (see http://genesdev.cshlp.org/site/misc/terms.xhtml). After six months, it is available under a Creative Commons License (Attribution-NonCommercial 4.0 International), as described at http://creativecommons.org/licenses/by-nc/4.0/. 
mainly by ERL1 to enforce stomatal spacing (Shpak et al. 2005; Hara et al. 2007, 2009; Hunt and Gray 2009; Lee et al. 2012). Expressed in mesophyll cells, EPFL9 competes with EPF2 for ER receptor binding, which acts to inhibit receptor function and promote stomatal development (Hunt et al. 2010; Kondo et al. 2010; Sugano et al. 2010; Ohki et al. 2011; Lee et al. 2015).

Another process involving ERf signaling is the elongation of aboveground plant organs, which is regulated primarily by vasculature-localized ERfs. A different subset of EPF family ligands, EPFL6/CHALLAH (CHAL) and EPFL4/CHALLAH-LIKE2 (CLL2), is expressed in endodermal cells and is perceived by vasculature-localized ERfs (Abrash et al. 2011; Uchida et al. 2012). Based on the phenotype of the tmm-1 mutant and the absence of its expression in vasculature, TMM does not regulate the elongation of aboveground plant organs (Nadeau and Sack 2002; Shpak et al. 2005; Abrash et al. 2011).

The precise role of TMM in stomata development has remained ambiguous. TMM is an indispensable component of the ERf signaling pathway in stomatal development (Shpak et al. 2005; Lee et al. 2012), but the phenotype of tmm-1 is tissue-dependent. In stems, the tmm-1 mutant has no stomata, while leaves exhibit a profusion of stomata in clusters (Yang and Sack 1995; Geisler et al. 1998, 2000; Shpak et al. 2005). Interestingly, while mutations in the EPFL4 and EPFL6 genes have no impact on stomata development, their overexpression inhibits stomata formation, especially in the tmm-1 background (Abrash and Bergmann 2010; Abrash et al. 2011). Genetic evidence suggests that, in the epidermis, TMM can act as a specificity factor for ERf signaling by promoting ERf perception of EPF1,2 and EPFL9 but preventing perception of EPFL4,6 (Abrash et al. 2011; Lee et al. 2012, 2015). However, the mechanism of how TMM modulates different signaling with specific ligands has remained elusive.

In the present study, we provide multiple lines of evidence showing that only in complex with TMM can ERfs function as the receptor of EPF1, EPF2, or EPFL9. In contrast, an ERf alone is sufficient for recognition of EPFL4 or EPFL6, and, in fact, TMM interferes with their interaction with ERfs. EPFL9 competes with EPF1 and EPF2 to bind ERf ${ }^{\text {LRR }}-T_{M} M^{\text {LRR }}$ in vitro. Collectively, these data demonstrate that TMM enables ERf to discriminate between a variety of ligands, and this capability, in concert with tissue-specific expression of TMM, provides a mechanism for tissue-specific function of ERf receptors and their ligands.

\section{Results}

TMM forms a ligand-independent complex with ER, ERL1, or ERL2

Genetic and biochemical data show that TMM interacts with ERfs in vivo (Shpak et al. 2005; Lee et al. 2012). Ligand-induced interaction with coreceptors has been demonstrated for many LRR-RKs (Song et al. 2016), but whether TMM-ERf complexes are EPF-promoted has remained unknown. To address this question, we purified the extracellular LRR domain proteins of ER, ERL1, and ERL2 (ER ${ }^{\mathrm{LRR}}$, ERL1 ${ }^{\mathrm{LRR}}$, and ERL2 $\left.{ }^{\mathrm{LRR}}\right)$ from insect cells. However, purification of the TMM ${ }^{\mathrm{LRR}}$ protein was unsuccessful using the same strategy. Given the interaction of TMM and ERfs in plants (Shpak et al. 2005; Lee et al. 2012), we coexpressed TMM ${ }^{\text {LRR }}$ individually with the three ERfs in the hope of facilitating purification of the RLP. Indeed, $T M M^{L R R}$ was well expressed when coexpressed with $E R^{\mathrm{LRR}}$ or ERL1 ${ }^{\mathrm{LRR}}$ in insect cells (Supplemental Fig. S2). Gel filtration assays showed that $\mathrm{TMM}^{\mathrm{LRR}}$ formed a stable complex with $\mathrm{ER}^{\mathrm{LRR}}$ or ERL1 ${ }^{\mathrm{LRR}}$ with a stoichiometry of $\sim 1: 1$, as indicated by their intensity on SDS-PAGE (Supplemental Fig. S2). However, for unknown reasons, we failed to obtain the ERL2 ${ }^{\mathrm{LRR}}$ $\mathrm{TMM}^{\mathrm{LRR}}$ complex using the coexpression strategy. Nonetheless, these results indicate that, in vitro, both ER and ERL1 form constitutive complexes with TMM through their extracellular domains.

To understand the molecular mechanism underlying TMM-ERf interaction, we solved the crystal structure of the ERL1 ${ }^{\text {LRR }}$ TMM ${ }^{\text {LRR }}$ complex at a resolution of $3.05 \AA$ (Fig. 1A; Supplemental Table S1). Nearly the whole concave surface of $T_{M M}{ }^{\mathrm{LRR}}$ interacts with the $\mathrm{N}$-terminal half convex side of ERL1 ${ }^{\text {LRR }}$ but with a distortion of $\sim 30^{\circ}$. TMM ${ }^{\mathrm{LRR}}$ and ERL $1^{\mathrm{LRR}}$ have extensive interactions, burying a surface area of $1614 \AA^{2}$. The concave surface of $\mathrm{TMM}^{\mathrm{LRR}}$ features neutral charges at the center and positive charges at the periphery (Fig. 1B). The charged surfaces of $T M M^{L R R}$ are complementary to those of ERL1 ${ }^{\text {LRR }}$ at the N-terminal side, whereas the neutral surface forms van der Waals contacts with ERL1 ${ }^{\text {LRR }}$ (Fig. 1B). TMM TM167 $^{\text {Rin }}$ is located at the center of the charged interface and forms a pair of hydrogen bonds with the carbonyl oxygen of $\mathrm{ERL1}^{\mathrm{P} 167}$, whereas a hydrogen bond is established between ERL1 ${ }^{\mathrm{N} 168}$ and $\mathrm{TMM}^{\mathrm{R} 141}$ (Fig. 2A). At the periphery of the interface, several polar interactions involving $\mathrm{TMM}^{\mathrm{S} 109, \mathrm{D} 110, \mathrm{~K} 257}$ are made with their respective neighboring residues of ERL1. Additionally, hydrophobic contacts made by $\mathrm{TMM}^{\mathrm{L} 108,} \mathrm{~F} 138$, V233 with ERL1 further fortify interactions of this interface (Fig. 2A). At the center of the other interface are TMM L281, M307, M330, I331, V355, which form hydrophobic contacts with ERL1 ${ }^{\text {LRR }}$ (Fig.' 2A). However, hydrogen and salting bonds appear to dominate the periphery interactions of this interface (Fig. 2A). Structure-based sequence alignment indicated that the TMM-interacting residues of ERL1 are highly conserved among the ecto-LRR domains of ERfs (Supplemental Fig. S3A), suggesting that they all can constitutively interact with TMM.

To confirm the structure of TMM ${ }^{\mathrm{LRR}}-\mathrm{ERL} 1^{\mathrm{LRR}}$, we mutated residues from the interfaces between the two LRRs and individually coexpressed the mutants with their wild-type partners in insect cells. We then used pulldown assays to examine the interaction of the mutant proteins with wild-type $T M M^{\mathrm{LRR}}$ or ERL1 ${ }^{\mathrm{LRR}}$. As shown in Figure $2 \mathrm{~B}$, wild-type His-tagged ERL1 $1^{\mathrm{LRR}}$ failed to pull down the mutant protein of $\mathrm{TMM}^{\mathrm{LRR}} \mathrm{L} 281 \mathrm{D}$ or

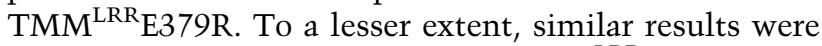
obtained for the mutant protein $E R L 1{ }^{\mathrm{LRR}} \mathrm{E} 114 \mathrm{R}$ with wild-type $\mathrm{TMM}^{\mathrm{LRR}}$. To further support the biochemical 
A

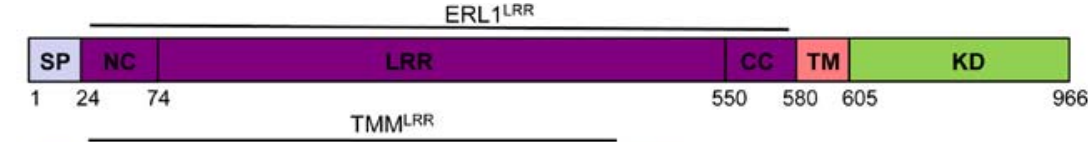

\begin{tabular}{|l|c|c|c|c|c|}
\cline { 2 - 6 } & SP & NC & LRR & \multicolumn{1}{c|}{ CC } & TM \\
\hline 1 & 24 & 123 & 400 & 470 & 496
\end{tabular}
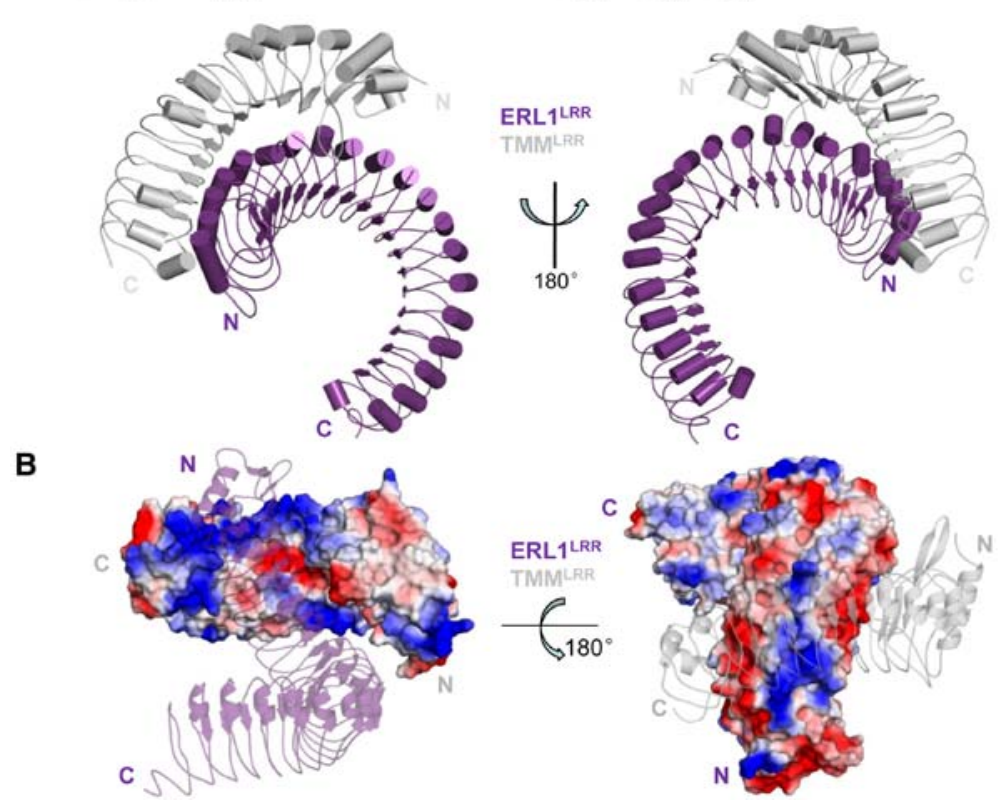

Figure 1. Overall structure of the ERL1 $^{\text {LRR}}-$ TMM $^{\text {LRR }}$ complex. (A) Overall structure of the ERL1 ${ }^{\text {LRR }}-$ TMM $^{\text {LRR }}$ complex. " $\mathrm{N}$ " and " $\mathrm{C}$ " represent the $\mathrm{N}$ terminus and $\mathrm{C}$ terminus, respectively. Color codes are indicated. Schematic representations of the domain structures of ERL1 $1^{\mathrm{LRR}}$ and $\mathrm{TMM}^{\mathrm{LRR}}$ are shown at the top. (SP) Signal peptide; (NC) N-terminal capping; (CC) C-terminal capping; (TM) transmembrane; (KD) kinase domain. (B) Surface representation of the electrostatic potential of ERL $1^{\text {LRR }}-\mathrm{TMM}^{\mathrm{LRR}}$. The electrostatic potential of TMM ${ }^{\mathrm{LRR}}$ and a cartoon representation of ERL1 $1^{\mathrm{LRR}}$ in transparency are shown at the left. The right panel shows the electrostatic potential of ERL1 $1^{\text {LRR }}$ and a cartoon representation of $\mathrm{TMM}^{\mathrm{LRR}}$ in transparency. (White) Neutral surface; (blue) positive surface; (red) negative surface; (N) N terminus; (C) C terminus. Color codes are indicated. data, we generated transgenic Arabidopsis plants and investigated the effects of ERL1 ${ }^{\mathrm{E} 114 \mathrm{R}}, \mathrm{TMM}^{\mathrm{L} 281 \mathrm{D}}$, and $\mathrm{TMM}^{\mathrm{E} 379 \mathrm{R}}$ on stomatal development. As observed previously, clustered stomata and no stomata were observed in cotyledons and stems of tmm mutant plants, respectively (Geisler et al. 1998; Shpak et al. 2005). Expression of wild-type TMM in the tmm-1 mutant restored the stomata patterning of mutant plants to the levels of wild-type plants (Fig. 2C). In contrast, three independent transgenic lines of plants expressing TMM::TMM ${ }^{E 379 R}$ had stomatal patterning similar to the tmm mutant plants, indicating the loss of TMM function with this substitution (Fig. $2 C)$. Intriguingly, stems from the three $\mathrm{TMM}^{\mathrm{E} 379 \mathrm{R}}$ lines only partially phenocopied the tmm mutant, with stomata being present, although fewer than in the wildtype plants. However, a wild-type stomata phenotype was observed in plants expressing ERL1::ERL1 $1^{\mathrm{E} 114 \mathrm{R}}$ in the er erl1 erl2 mutant or TMM::TMM ${ }^{L 281 D}$ in the $t m m$ 1 mutant. We speculate that, in vivo, when coreceptors are properly aligned, due to their attachment to the plasma membrane, these single-point mutations are unable to disrupt their interactions. Overall, our biochemical, structural, and functional data support the idea that TMM and ERf form constitutive complexes.

The constitutive ERL1 $1^{L R R}-T M M^{L R R}$ complex recognizes EPF1/2

We then investigated whether the constitutive $\mathrm{ER}^{\mathrm{LRR}}$ $\mathrm{TMM}^{\mathrm{LRR}}$ or ERL1 ${ }^{\mathrm{LRR}}-\mathrm{TMM}^{\mathrm{LRR}}$ complex is able to interact with EPF1 or EPF2. Our pull-down assays showed that none of the three ERf proteins displayed interaction with these two EPFs (Fig. 3A). These results were further supported by gel filtration (Supplemental Fig. S4A,B). While ER ${ }^{\mathrm{LRR}}$ or ERL1 ${ }^{\mathrm{LRR}}$ alone showed no binding to EPF1/EPF2, complexing with $\mathrm{TMM}^{\mathrm{LRR}}$ resulted in their strong interaction with these two EPF peptides, as indicated by their comigration under the gel filtration assay (Fig. 3B; Supplemental Fig. S5). To further verify these results, we used isothermal titration calorimetry (ITC) to quantify interaction of the ERL $1^{\text {LRR }}-$ TMM $^{\text {LRR }}$ complex with EPF1 or EPF2 (Fig. 3C). In support of the data from gel filtration, the ITC results indicated that EPF1 or EPF2 strongly interacted with ERL1 ${ }^{\mathrm{LRR}}-\mathrm{TMM}^{\mathrm{LRR}}$, with dissociation constants of $1.3 \mu \mathrm{M}$ and $1.1 \mu \mathrm{M}$, respectively. In contrast, the ERL $1^{\text {LRR }}$ protein alone had no detectable binding to these two EPFs under the ITC assays, further supporting the pull-down data (Fig. 3A). Taken together, our results indicate that ERfs and TMM form constitutive complexes for the recognition of EPF1 and EPF2 in vitro.

To probe the molecular mechanism of how TMM ${ }^{\mathrm{LRR}}$ ERL1 ${ }^{\mathrm{LRR}}$ recognizes EPF1 and EPF2, we solved the crystal structures of the tertiary complexes ERL1 ${ }^{\text {LRR }}-$ TMM $^{\text {LRR }}$ EPF1 (Fig. 4A; Supplemental Table S1) and ERL1 ${ }^{\mathrm{LRR}_{-}}$

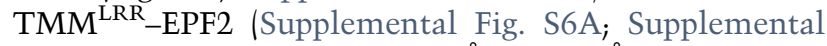
Table S1) at resolutions of $2.63 \AA$ and $3.5 \AA$, respectively. Structural comparison showed that the two complexes are highly conserved (Supplemental Fig. S6B). We therefore limit our discussions to the structure of the complex with a higher resolution. In this structure, EPF1 assumes an inverted V-shaped architecture and binds to the groove created by TMM ${ }^{\text {LRR }}$ and ERL1 ${ }^{\text {LRR }}$ (Fig. 4A). This 
Lin et al.

A

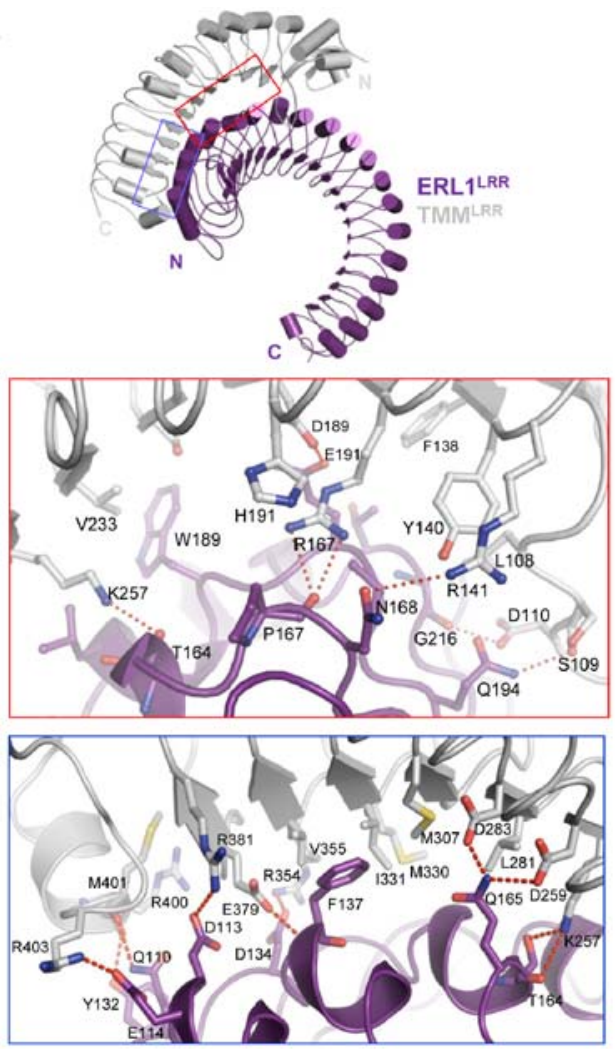

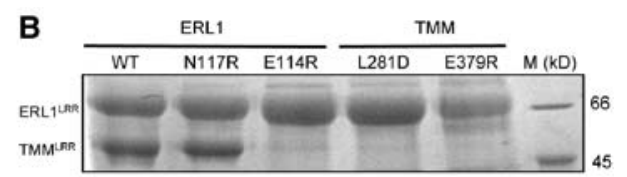

C
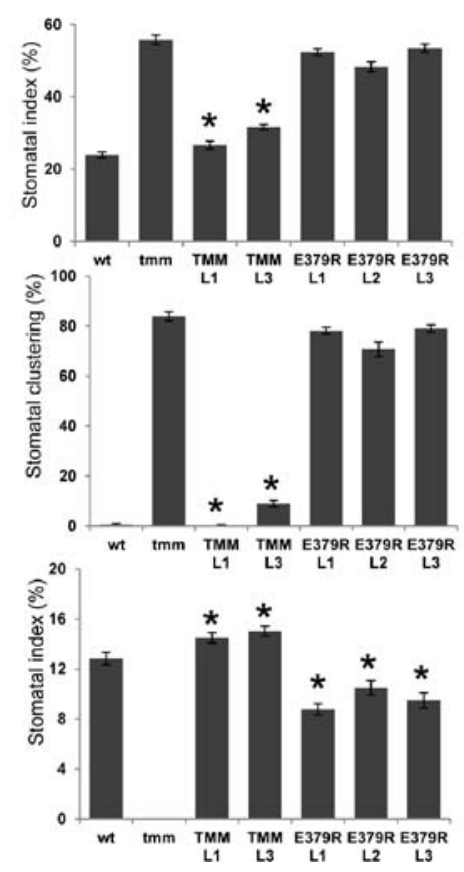

Figure 2. Mechanism of ERL1 ${ }^{\mathrm{LRR}}-\mathrm{TMM}^{\mathrm{LRR}}$ interaction. $(A)$ Detailed interactions of ERL1 ${ }^{\mathrm{LRR}}$ with $\mathrm{TMM}{ }^{\mathrm{LRR}}$. Interaction regions are indicated by red and blue squares in the top panel. Red dashed lines indicate hydrogen bonds or salt bridges. $(B)$ Mutagenesis analysis of the ERL1-TMM interaction in vitro. Mutant ERL1 or TMM was coexpressed with its wild-type partners in insect cells. C-terminally 6xHistagged ERL1 ${ }^{\mathrm{LRR}}$ was pulled down by $\mathrm{Ni}^{+}$beads. The bound proteins were eluted and visualized by Coomassie blue staining following SDSPAGE. $(C)$ The TMM E379R reduces the functionality of TMM in plants. The stomatal index (top) and stomatal clustering (middle) were analyzed on the abaxial side of 14-d-old cotyledons of wild-type (wt), tmm, and T2 generation seedlings expressing functional TMM (two independent lines) or TMM with E379R substitution in the tmm background (three independent lines). The stomatal index was analyzed on the mature stem (bottom) of wild-type, tmm, and T2 generation plants expressing functional TMM or TMM with E379R substitution in the $t m m$ background. Values are means \pm SE. $N=18-30$. Values significantly different from the tmm mutant $(P<0.0001)$ are indicated by asterisks.

structural observation supports our biochemical data that both TMM ${ }^{\mathrm{LRR}}$ and ERL1 ${ }^{\mathrm{LRR}}$ were required for interaction with EPF1 or EPF2. Structure comparison showed that no striking conformational changes occur to the ERL1 ${ }^{\text {LRR }}$ $\mathrm{TMM}^{\mathrm{LRR}}$ complex following EPF1 binding (Supplemental Fig. S6C). Similar to the solution structure of EPFL9 (Ohki et al. 2011), a long anti-parallel $\beta$ sheet constitutes the core of the EPF1 structure, with the $\mathrm{N}$-terminal loop region packing against one side of the anti- $\beta$ sheet, and a short $\beta$ strand from the $\mathrm{C}$-terminal side pairing with the anti- $\beta$ sheet (Fig. 4A; Supplemental Fig. S6B). No electron density was found around the hairpin loop of EPF1, consistent with the structural study of EPFL9 showing that multiple conformations were found at the equivalent region of EPFL9 in solution (Ohki et al. 2011). Interestingly, this region of EPFs has been suggested to be important for conferring their functional specificity (Ohki et al. 2011).

The three parts of EPF1 interact with the ERL1 ${ }^{\mathrm{LRR}}$ TMM $^{\text {LRR }}$ complex (Fig. 4A). The N-terminal loop of EPF1 is sandwiched between two consecutive LRRs of
ERL1 ${ }^{\text {LRR }}$, and the interactions around this region are mediated mainly by polar contacts (Fig. 4B). At the center of this interface is $\mathrm{EPF}^{\mathrm{Ser} 3}$, which hydrogen-bonds with

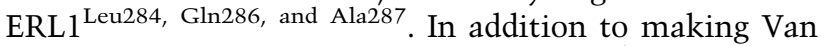
der Waals contacts with ERL1 ${ }^{\text {Leu284 }}$, EPF1 ${ }^{\text {Gly2 }}$ establishes a hydrogen bond with ERL1 ${ }^{\text {Gln263 }}$. These two EPF1 residues (called the "GS" motif here) are highly conserved among all of the EPF members (Supplemental Fig. S3B). Additionally, EPF1 $1^{\text {Leu5 }}$ hydrophobically packs against

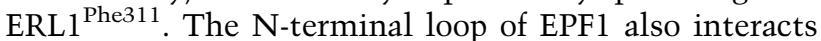
with $\mathrm{TMM}^{\mathrm{LRR}}$ through His10 (aromatic), Ala11, and Gly13, which stack tightly against Ile77, Trp85, and Trp73 of TMM, respectively (Fig. 4C). The TMM ${ }^{\mathrm{LR}}$ EPF1 interaction is further strengthened by Pro50 and Pro52 from the C-terminal side of EPF1, with the former residue packing against $\mathrm{T} 112$ and Ala113 of TMM ${ }^{\mathrm{LRR}}$, and the latter residue stacking against Trp85 and His86 of $\mathrm{TMM}^{\mathrm{LRR}}$ (Fig. 4C). It is of interest to note that some of the TMM-interacting residues of EPF1 are largely conserved in EPF2 but not in EPFL4,5,6 (Supplemental Figs. 
A

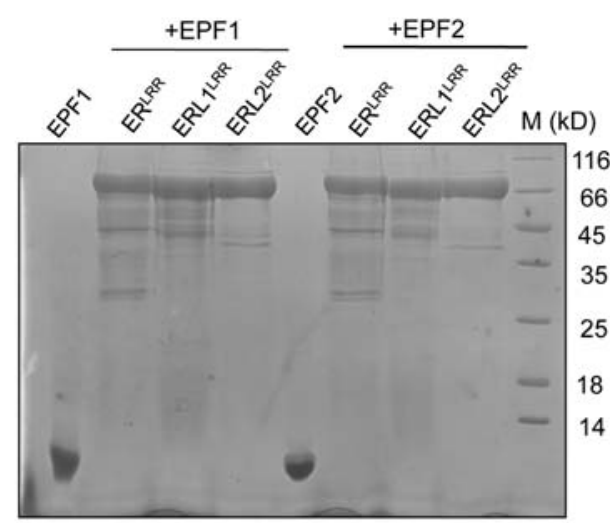

B

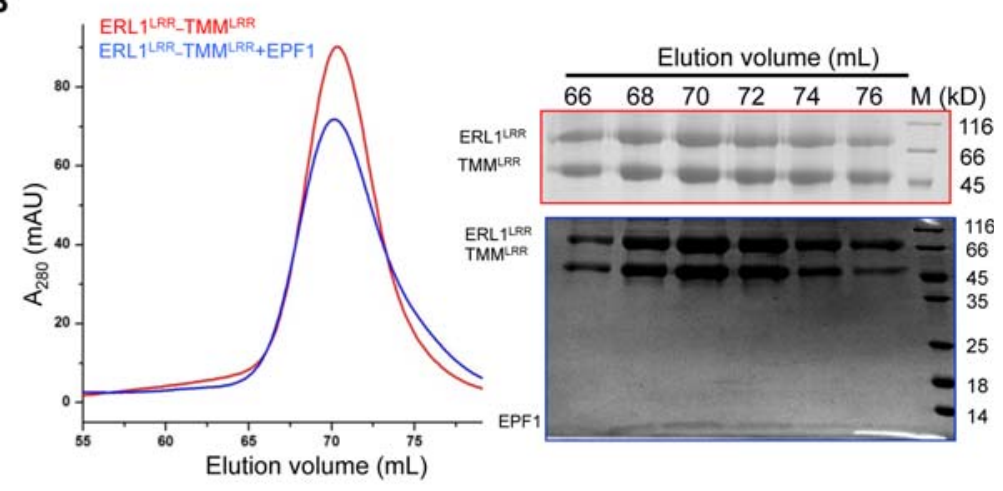

C

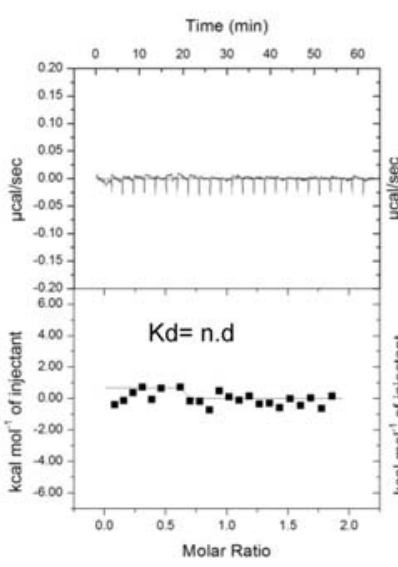

EPF1 to ERL1LRR

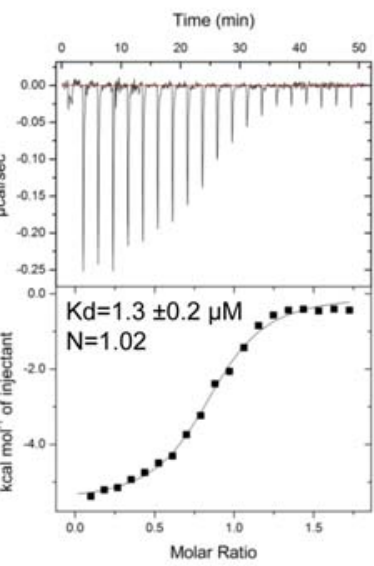

EPF1 to ERL1 $1{ }^{L R R}-T M M M^{L R R}$

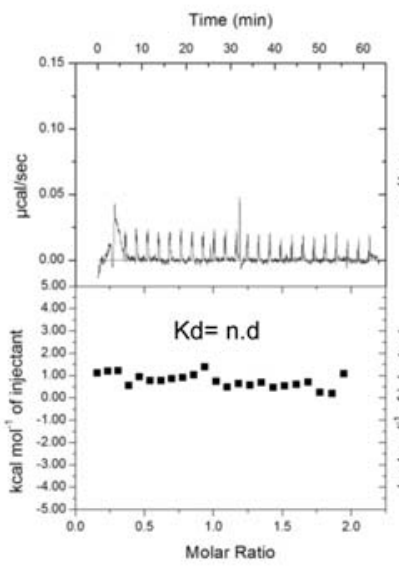

EPF2 to ERL1 1 RRR

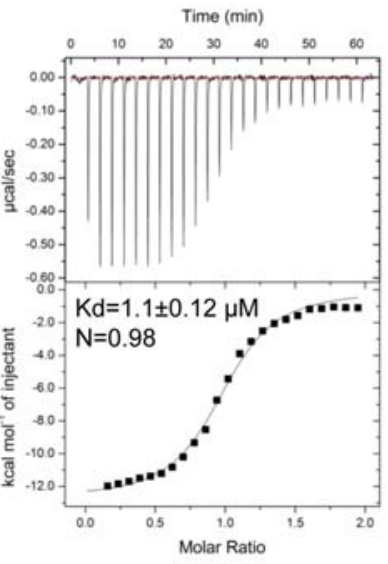

EPF2 to ERL1 ${ }^{\text {LRR-TMMLRR }}$

Figure 3. ERL1-TMM complexes function as receptors of EPF1 and EPF2 in vitro. $(A)$ ERfs alone fail to interact with EPF1 or EPF2 in pulldown assays. The $6 \mathrm{xHis}$-tagged $\mathrm{ER}{ }^{\mathrm{LRR}}, \mathrm{ERL1} 1^{\mathrm{LRR}}$, and ERL2 ${ }^{\mathrm{LRR}}$ were incubated individually with EPF1 or EPF2, and the mixtures were then flowed through Ni-NTA beads. After extensive washing, the bound proteins were eluted and analyzed with SDS-PAGE followed by Coomassie blue staining. (B) EPF1 directly binds to the ERL1 ${ }^{\text {LRR }}-$ TMM $^{\mathrm{LRR}}$ complex. (Left panel) Size exclusion chromatography analysis of the interaction between EPF1 and ERL1 ${ }^{\mathrm{LRR}}-\mathrm{TMM}^{\mathrm{LRR}}$; the elution volumes and the molecular weight markers are indicated at the top. (Right panel) SDS-PAGE analysis of peak fractions from the left panel. (C) Quantification of the binding affinity of EPF1 (left) or EPF2 (right) to ERL1 ${ }^{\mathrm{LRR}}$ or ERL1 ${ }^{\mathrm{LRR}}-\mathrm{TMM}^{\mathrm{LRR}}$ by ITC. (nd) No detectable binding. EPF1 or EPF2 was titrated into ERL1 ${ }^{\mathrm{LRR}}$ or ERL1 ${ }^{\mathrm{LRR}}-$ $\mathrm{TMM}^{\mathrm{LRR}}$ protein in the ITC cell. Integrated heat measurements from ITC are shown. The calculated stoichiometry $(\mathrm{N})$ and the dissociation constant $\left(K_{\mathrm{d}}\right)$ are indicated.

S3B, S6D). The inner surface of ERL1 ${ }^{\mathrm{LRR}}$ interacts with one $\beta$ strand of EPF1 (Fig. 4D). ERL1 ${ }^{\text {Thr266 }}$ from underneath forms a pair of hydrogen bonds with EPF1 ${ }^{\text {Met38, }}$ which also packs against ERL1 ${ }^{\text {Val290. }}$. Hydrophobic contacts made by Ala265 and Ala289 of ELR1 with EPF1 ${ }^{\text {Tyr40 }}$ further fortify the interaction around this region.

To further verify the structure of the TMM ${ }^{\mathrm{LRR}}$ ERL1 ${ }^{\text {LRR }}$-EPF1 complex, we mutated some of the critical residues in EPF1 that interact with TMM $^{\text {LRR }}$ or ERL1 ${ }^{\text {LRR }}$ and then tested the interaction of these mutant EPF1 proteins with the TMM ${ }^{\mathrm{LRR}}$-ERL1 ${ }^{\mathrm{LRR}}$ complex. In support of the structural observation, mutation of Ser3 from the "GS" motif compromised the interaction of EPF1 with the TMM $^{\text {LRR }}$-ERL1 ${ }^{\text {LRR }}$ complex, as indicated by pulldown assays using tagged EPF1 (Fig. 4E). Similar observations were made with mutations of EPF1 ${ }^{\mathrm{G} 13}$ and EPF1 ${ }^{\mathrm{P} 50}$ that pack against $\mathrm{TMM}^{\mathrm{LRR}}$. Consistent with previous data (Lee et al. 2012), treatment of Arabidopsis with wild-type EPF1 strikingly reduced the number of stomata in cotyledons (Fig. 4F). In contrast, the activity of EPF1 was reduced substantially by the three EPF1 mutations, in particular EPF1 ${ }^{\mathrm{S} 3 \mathrm{R}}$ and EPF1 ${ }^{\mathrm{P} 50 \mathrm{R}}$ (Fig. 4F).

\section{EPFL9 competes with EPF1 and EPF2 to bind ERf $f^{L R R}$ $T M M^{L R R}$}

EPFL9 was shown recently to compete with EPF2 for interaction with ER, thus promoting stomatal development (Lee et al. 2015). Our data demonstrate that ERfs and TMM form constitutive complexes for the recognition of EPF1 and EPF2. We then investigated whether the ERL1 ${ }^{\text {LRR }}$ protein alone or the constitutive ERL1 ${ }^{\text {LRR }}$ TMM $^{\text {LRR }}$ complex is able to interact with EPFL9 using gel filtration. The assay showed that a tiny amount of 
Lin et al.
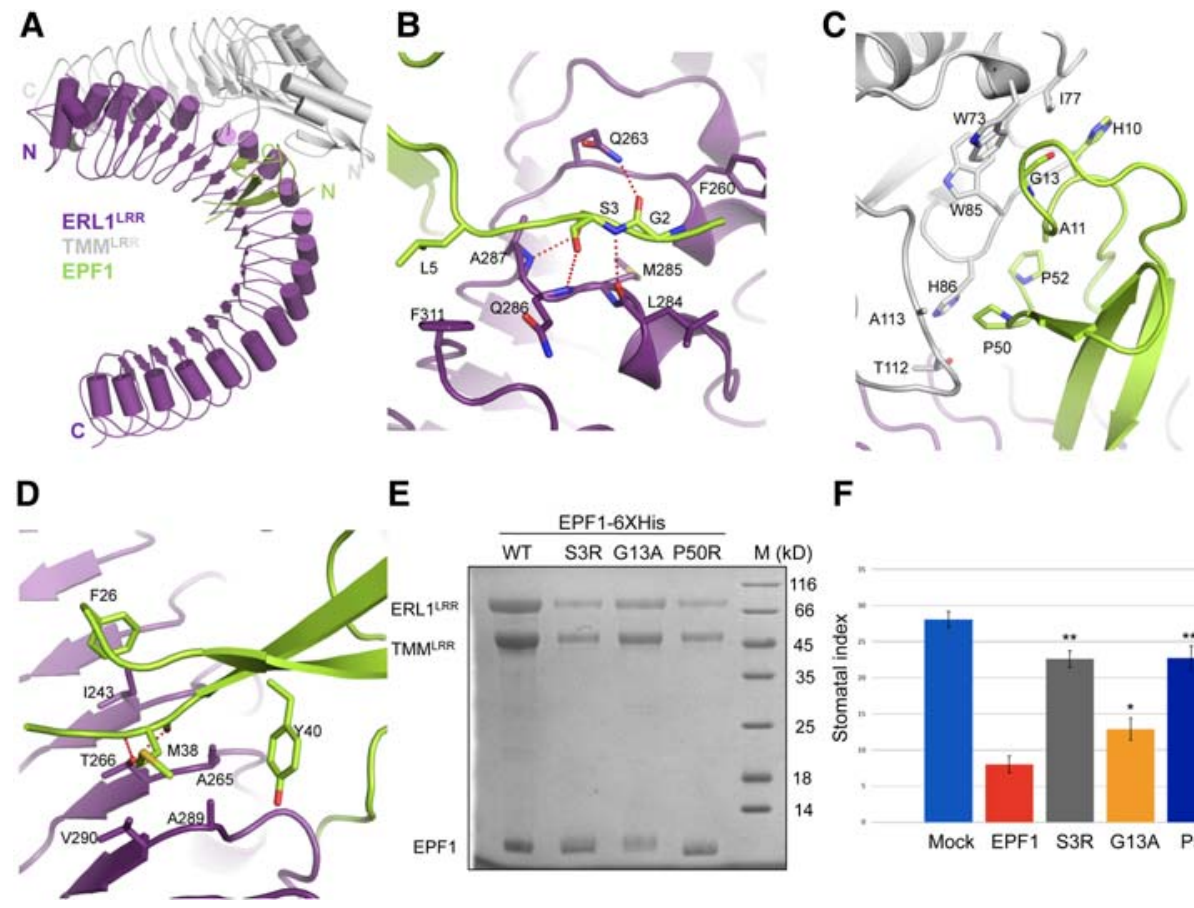

E

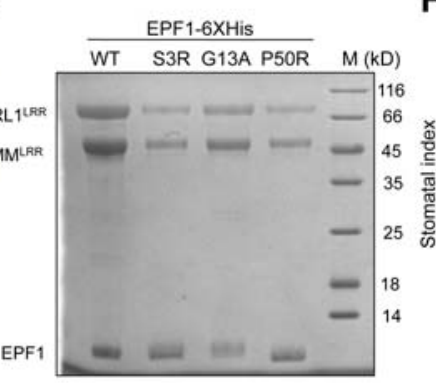

$\mathbf{F}$

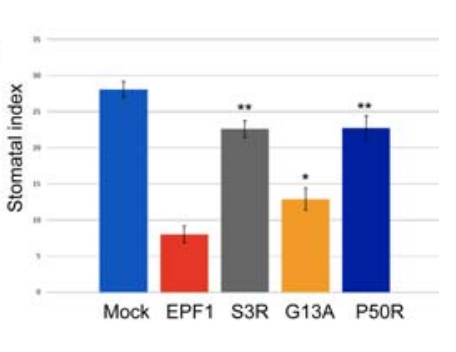

Figure 4. Recognition mechanism of EPF1 by ERL1 ${ }^{\mathrm{LRR}}-\mathrm{TMM}^{\mathrm{LRR}} \cdot(A)$ Overall structure of the EPF1-ERL1 ${ }^{\mathrm{LRR}}-\mathrm{TMM}{ }^{\mathrm{LRR}}$ complex. $^{\mathrm{L}}$ ) $\mathrm{N}$ terminus; $(C) C$ terminus. Color codes are indicated. $(B)$ Detailed interactions of the $\mathrm{N}$-terminal side of EPF1 with ERL1 $1^{\mathrm{LRR}}-\mathrm{TMM}{ }^{\mathrm{LRR}}$. $(C)$ Detailed interactions of the central region of EPF1 with ERL1 ${ }^{\mathrm{LRR}}-\mathrm{TMM}^{\mathrm{LRR}}$. $(D)$ Detailed interactions of EPF1 with ERL1 ${ }^{\mathrm{LRR}}-\mathrm{TMM}{ }^{\mathrm{LRR}} \cdot(E)$ Mutagenesis analysis of EPF1-6xHis's interaction with ERL1 ${ }^{\mathrm{LRR}}-\mathrm{TMM}^{\mathrm{LRR}}$ in vitro. The pull-down assays were performed as described in Figure 3A. $(F)$ Effects of the mutations of EPF1 on the stomatal density of Arabidopsis cotyledons; the concentration of peptide was $10 \mu \mathrm{M}$. The error bars show SD. $n>8 .\left({ }^{*}\right) P<0.05 ;\left(^{* *}\right) P<0.01$, versus the controls by Student's $t$-test.

EPFL9 comigrated with ERL1 ${ }^{\text {LRR }}$, indicating a weak interaction between them (Supplemental Fig. S4C). In contrast, when the ERL1 $1^{\text {LRR }}-$ TMM ${ }^{\text {LRR }}$ complex protein was used for the assay, much more EPFL9 was shifted to a highermolecular-weight species and comigrated with the complex (Fig. 5A). This result showed that complexing with $T M M^{\mathrm{LRR}}$ greatly promotes ERL1 ${ }^{\mathrm{LRR}}$ recognition of EPFL9. These gel filtration data were confirmed further by our ITC assays showing that EPFL9 bound to the ERL1 ${ }^{\text {LRR }}$ TMM ${ }^{\text {LRR }}$ complex with an affinity of $4 \mu \mathrm{M}$, $\sim 10$ times higher than that of its binding to ERL1 ${ }^{\text {LRR }}$ alone (Fig. 5B). Next, we tested whether EPFL9 is able to compete with EPF2 or EPF1 for binding to the ER ${ }^{\text {LRR }}-T_{M} M^{\mathrm{LRR}}$ or ERL1 ${ }^{\text {LRR }}-$ TMM $^{\text {LRR }}$ complex. To this end, we individually incubated the complexes with the C-terminally Histagged EPF1 or EPF2. Purification of the mixture using Ni-resin showed that increasing concentrations of EPFL9 gradually decreased the amount of $\mathrm{ER}^{\mathrm{LRR}}$ $\mathrm{TMM}^{\mathrm{LRR}}$ or ERL1 ${ }^{\mathrm{LRR}}-\mathrm{TMM}{ }^{\mathrm{LRR}}$ pulled down by EPF2 or EPF1, indicating that EPFL9 and these two EPFs compete with each other for binding to the ERf ${ }^{\mathrm{LRR}}-\mathrm{TMM}^{\mathrm{LRR}}$ complex (Fig. 5C).

\section{EPFL4/6 interacts with ER, ERL1, or ERL2 with} no need of TMM

In contrast to EPF1,2, which are specialized for stomatal regulation, CHAL-related family members (EPFL4,5,6) ap- pear to be dedicated to growth regulatory processes. Genetic evidence has suggested that ERfs also function as receptors of EPFL4,5,6 (Abrash et al. 2011; Uchida et al. 2012). To further support this conclusion, we used pulldown and gel filtration to assay the interaction of EPFL4 with $\mathrm{ER}^{\mathrm{LRR}}, \mathrm{ERL} 1^{\mathrm{LRR}}$, or ERL2 ${ }^{\mathrm{LRR}}$. In contrast to EPF1,2, EPFL4 interacted strongly with all the three ERf proteins in the absence of TMM ${ }^{\mathrm{LRR}}$ (Fig. 6A,B). The EPFL4ERL1 ${ }^{\text {LRR }}$ interaction was further verified by our ITC assay showing that their binding affinity was $\sim 0.14 \mu \mathrm{M}$ (Fig. 6C). Unexpectedly, complexing with $\mathrm{TMM}^{\mathrm{LRR}}$ significantly compromised the binding affinity of ERL1 ${ }^{\text {LRR }}$ with EPFL4 $(1.3 \mu \mathrm{M})$, indicating that TMM blocks ERL1 ${ }^{\text {LRR }}$ recognition of EPFL4. Similar results were obtained with EPFL6 and the ERL1 ${ }^{\text {LRR }}-$ TMM $^{\text {LRR }}$ complex (Supplemental Fig. S7).

To elucidate the molecular mechanism underlying ERf recognition of EPFL4, we solved the crystal structure of ERL2 ${ }^{\text {LRR }}$ bound by EPFL4 (Fig. 7A; Supplemental Table S1). Like EPF1, EPFL4 also adopts an inverted V-shaped structure consisting of an anti-parallel $\beta$-sheet and a long N-terminal loop (Fig. 7A). These two structural elements mediate EPFL4's interaction with ERL2 ${ }^{\text {LRR }}$ by clamping one lateral side of the receptor. EPFL4 binding to ERL2 ${ }^{\text {LRR }}$ results in a structure resembling that of EPF1-ERL1 ${ }^{\text {LRR }}$ from the ternary complex ERL1 ${ }^{\text {LRR }}$

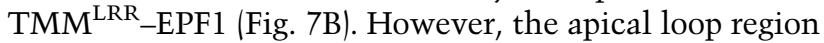
linking the first $\beta$ strand and the $\mathrm{N}$-terminal side of EPFL4 


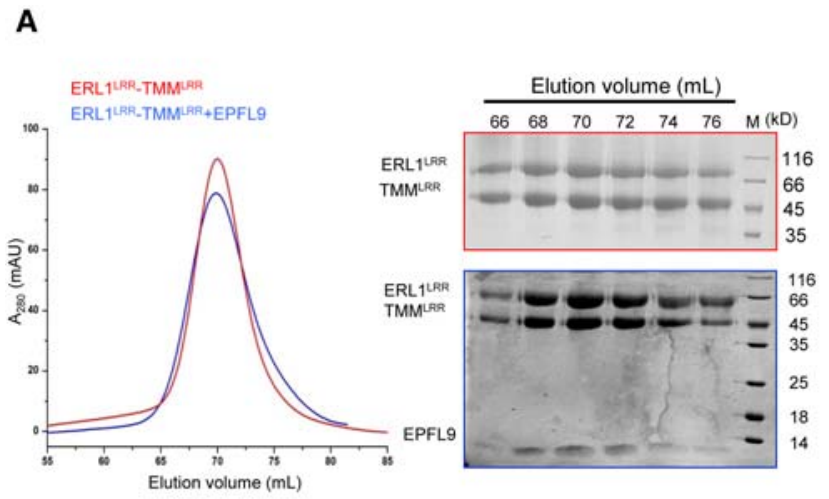

C

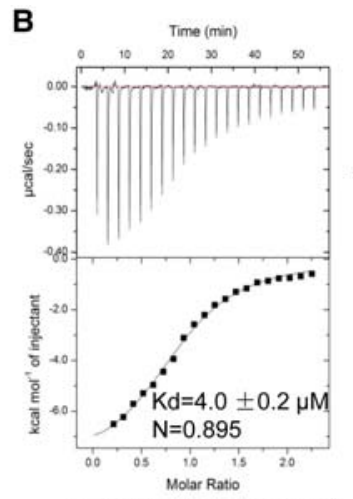

EPFL9 to ERL1LRR-TMMLRR

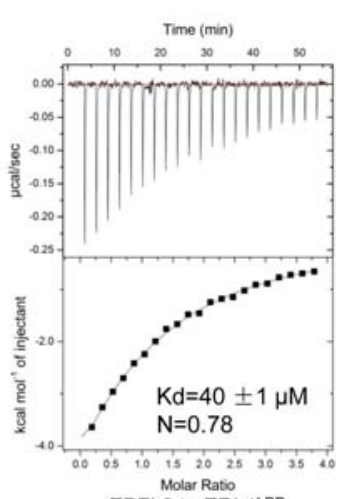

EPFL9 to ERL1 1 LRR

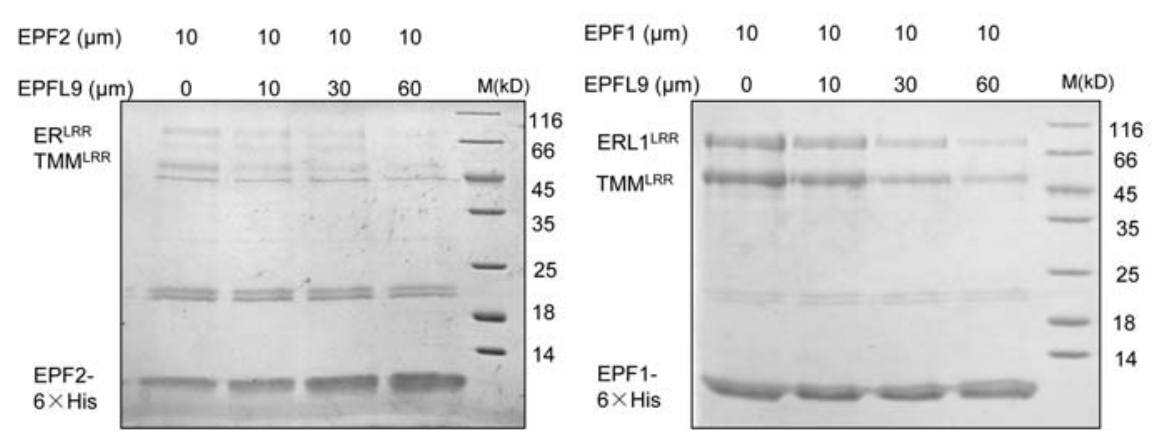

Figure 5. EPFL9 competes with EPF1 and EPF2 for binding to the ERf $\mathrm{LRR}_{-T M M}^{\mathrm{LRR}}$ complexes. (A, left panel) Size exclusion chromatography analysis of the interaction between EPFL9 and ERL1 ${ }^{\mathrm{LRR}}-\mathrm{TMM}^{\mathrm{LRR}}$. (Right panel) SDS-PAGE analysis of peak fractions from the left panel. The elution volumes and molecular weight markers are indicated at the top. (B) TMM promotes EPFL9 binding to ERL1 ${ }^{\text {LRR }}$. Quantification of the binding affinity of EPF9 with ERL1 $1^{\mathrm{LRR}}$ or ERL1 ${ }^{\mathrm{LRR}}-\mathrm{TMM}^{\mathrm{LRR}}$ by ITC. EPFL9 was titrated into ERL1 ${ }^{\mathrm{LRR}}$ or ERL1 $1^{\mathrm{LRR}}-$ $\mathrm{TMM}^{\mathrm{LRR}}$ protein in the ITC cell. Raw data (top panel) and integrated heat measurements (bottom panel) from ITC are shown. The calculated stoichiometry $(\mathrm{N})$ and the dissociation constant $\left(K_{\mathrm{d}}\right)$ are indicated. $(C)$ EPFL9 competes with EPF1,2 for binding to ERf ${ }^{\mathrm{LRR}}$ $\mathrm{TMM}^{\mathrm{LRR}} \cdot \mathrm{ER}^{\mathrm{LRR}}-\mathrm{TMM}^{\mathrm{LRR}}$ or ERL1 ${ }^{\mathrm{LRR}}-\mathrm{TMM}^{\mathrm{LRR}}$ was incubated with $10 \mu \mathrm{M}$ EPF2-6xHis or EPF1-6xHis with increasing concentrations of EPFL9 and subjected to $\mathrm{Ni}^{+}$resin. The bound proteins were eluted and further analyzed with SDS-PAGE followed by Coomassie blue staining.

was not well defined by electron density (Fig. 7A). In contrast, the equivalent regions of both EPF1 and EPF2 make contact with their C-terminal sides and interact with TMM $^{\text {LRR }}$ (Supplemental Fig. S8A). Ala11 conserved in EPF1 and EPF2 (Supplemental Fig. S3B) packs tightly against Pro52 and Val48 in the two peptides (Supplemental Fig. S8A). This amino acid is substituted with the bulkier lysine residue at the same position of EPFL4, which is expected to disrupt its local conformation. These structural differences provide an explanation of why TMM ${ }^{\mathrm{LRR}}$ reduces the binding affinity of EPFL4 with ERL1 ${ }^{\mathrm{LRR}}$ or ERL2 ${ }^{\mathrm{LRR}}$. To further support this model, we substituted the apical loop region of EPFL4 with that of EPF1 and assayed interaction of the swapped EPFL4 mutant (called EPFL4-EPF1) with ERL1 ${ }^{\text {LRR }}-$ TMM $^{\text {LRR }}$ using ITC. The results from the assay showed that EPFL4-EPF1 bound to the ERL1 ${ }^{\mathrm{LRR}}-\mathrm{TMM}^{\mathrm{LRR}}$ complex with an affinity of 0.42 $\mu \mathrm{M}$, which is approximately three times as high as that of wild-type EPFL4 to the same complex (Supplemental Fig. S8B).

The "GS" motif from the N-terminal loop of EPFL4 forms a set of polar interactions with ERL2 ${ }^{\text {LRR }}$ similar to those of EPF1 with ERL1 ${ }^{\text {LRR }}$ (Fig. 7C). ERL2 ${ }^{\text {M287 }}$ is the equivalent of $\mathrm{ER}^{\mathrm{M} 282}$, and mutation of this ERL2 residue is expected to perturb the local conformation of the $\mathrm{N}$-terminal loop-binding groove of ERL2 and consequently compromise ERL2's interaction with EPFL4. This is consistent with the reduced functionality of the $\mathrm{ER}^{\mathrm{M} 282 \mathrm{I}} \mathrm{mu}-$ tant (er-103) (Torii et al. 1996). Interaction of EPFL4 through its one $\beta$ strand with the inner surface of ERL2 ${ }^{\text {LRR }}$ buries a total surface area of $468.0 \AA^{2}$, which is much more extensive than that of EPF1 with the inner surface of ERL1 $^{\text {LRR }}\left(291.0 \AA^{2}\right)$ (Fig. 7D). This structural observation affords an explanation of why EPFL4 is recognized by ERL2 ${ }^{\mathrm{LRR}}$ in the absence of TMM. In addition to hydrogen-bonding with ERL2 ${ }^{\text {Thr268 }}$, EPFL4 ${ }^{\text {Glu37 }}$ that is substituted with Met38 in EPF1 forms a salt bridge with ERL2 $^{\text {Lys318 }}$ (Fig. 7D). Salt bridges are also established between EPFL4 ${ }^{\text {Arg40 }}$ and ERL2 ${ }^{\text {Glu244 }}$. Tyr40 of EPF1 is substituted with Trp39 in EPFL4, which makes a hydrogen bond with the carbonyl oxygen of Ala289 from ERL2. Compared with EPF1, EPFL4 has two more residues well defined in electron density from the C-terminal side of the ERL2 ${ }^{\mathrm{LRR}}$-interacting $\beta$ strand. One of these two 
Lin et al.

A

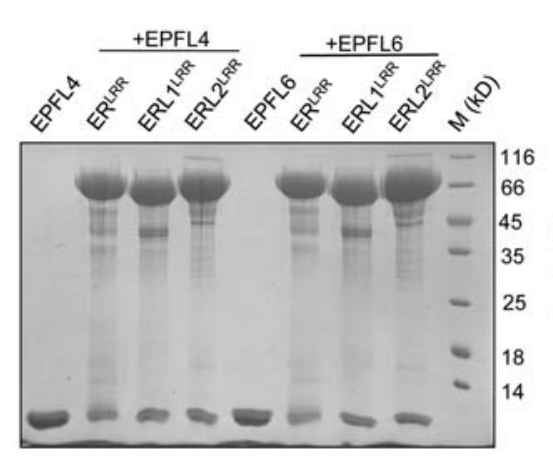

C

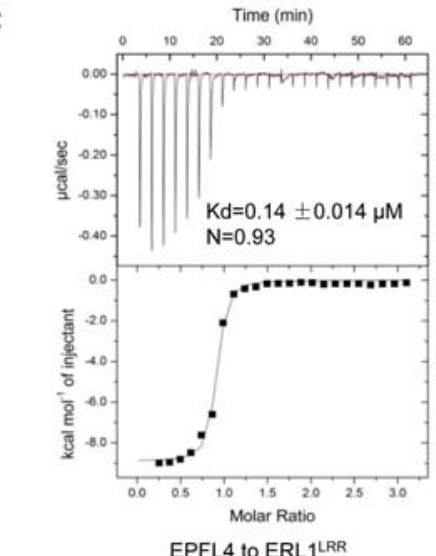

B

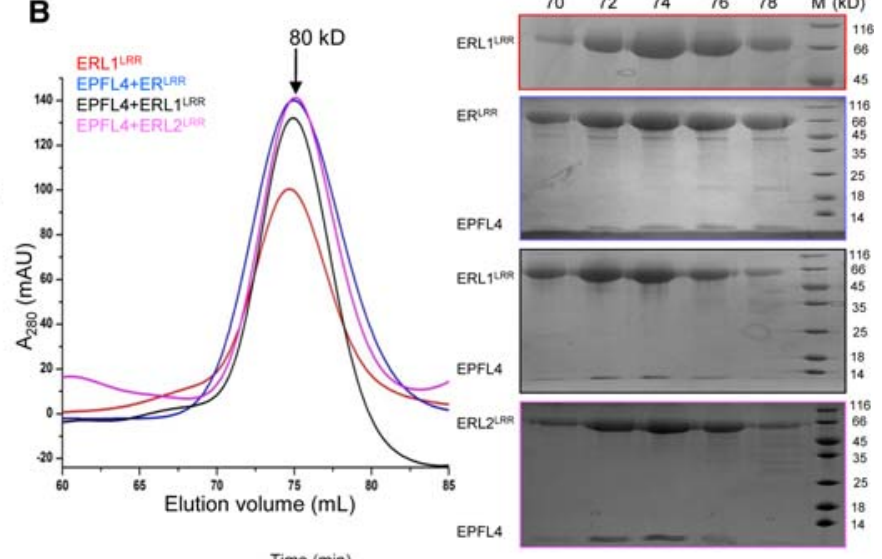

Figure 6. EPFL4 directly binds to ERfs independent of TMM. (A) ERfs alone are sufficient for interaction with EPFL4 or EPFL6. The 6xHis-tagged ER ${ }^{\mathrm{LRR}}, \mathrm{ERL}^{\mathrm{LRR}}$, or ERL2 ${ }^{\mathrm{LRR}}$ was incubated individually with EPFL4 or EPFL6 and subjected to $\mathrm{Ni}^{+}$resin. Next, the bound proteins were eluted from Ni-NTA and further analyzed by SDS-PAGE with Coomassie blue staining. (B, left panel) Size exclusion chromatography analysis of the interaction between EPFL4 and ERf ${ }^{\mathrm{LRR}}$. (Right panel) SDS-PAGE analysis of peak fractions from the left panel. $(C)$ TMM dampens EPFL4 binding to ERL1 $1^{\mathrm{LRR}}$ in vitro. Quantification of the binding affinity of EPFL4 with the ERL1 $1^{\mathrm{LRR}}$ or ERL $1^{\mathrm{LRR}}-$ $\mathrm{TMM}^{\mathrm{LRR}}$ by ITC. EPFL4 was titrated into ERL1 ${ }^{\mathrm{LRR}}$ or ERL1 ${ }^{\mathrm{LRR}}-\mathrm{TMM}^{\mathrm{LRR}}$ protein in the ITC cell. Raw data (top panel) and integrated heat measurements (bottom panel) from ITC are shown. The calculated stoichiometry $(\mathrm{N})$ and the dissociation constants $\left(\mathrm{K}_{\mathrm{d}}\right)$ are indicated.

residues, Tyr34, makes a pair of hydrogen bonds with

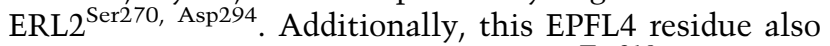
forms hydrophobic contacts with ERL2 ${ }^{\text {Tyr318 }}$. Structurebased sequence alignment showed that all of the amino acids critical for EPFL4 binding to ERL2 ${ }^{\mathrm{LRR}}$ are conserved among EPFL4,5,6 (Supplemental Fig. S3B).

\section{Discussion}

Here we provide several lines of evidence showing that TMM and ERfs form constitutive complexes. Our structural studies demonstrate that both TMM and ER/ERL1 are directly involved in the recognition of the stomatal regulatory peptides EPF1,2. These results indicate that the constitutive TMM-ERf complexes as a whole function as the receptors of the two peptides. ERfs, however, recognize the growth regulatory peptides EPFL4,6 independent of TMM. In stark contrast to EPF1,2, EPFL4,6 were greatly compromised in interaction with ERL1,2 in the presence of TMM. These results are consistent with previous genetic models (Abrash et al. 2011; Shpak 2013). Overall, our results together with others suggest that TMM endows ERfs with ligand specificity, allowing ERf-mediated signaling to regulate TMM-dependent stomatal development and TMM-independent responses (Supplemental Fig. S9). The requirement of TMM for EPF1,2 interaction with ERfs suggests that TMM might have evolved to specifically regulate stomatal development. This is in line with the genomic studies indicating that TMM is present only in land plants (Caine et al. 2016; Olsen et al. 2016) and the fact that TMM is expressed specifically in the epidermis but not in other tissues (Nadeau and Sack 2002; Shpak et al. 2005). The ligand specificity switch mechanism enabled by TMM offers an explanation for the tissue-dependent phenotypes of tmm knockout plants. In leaves, TMM deletion blocks the negative regulation of stomata development by EPF1,2-induced ERf signaling. In tmm stems where EPFL4, 6 are expressed, loss of the EPF1,2-induced ERf signaling activity would be 


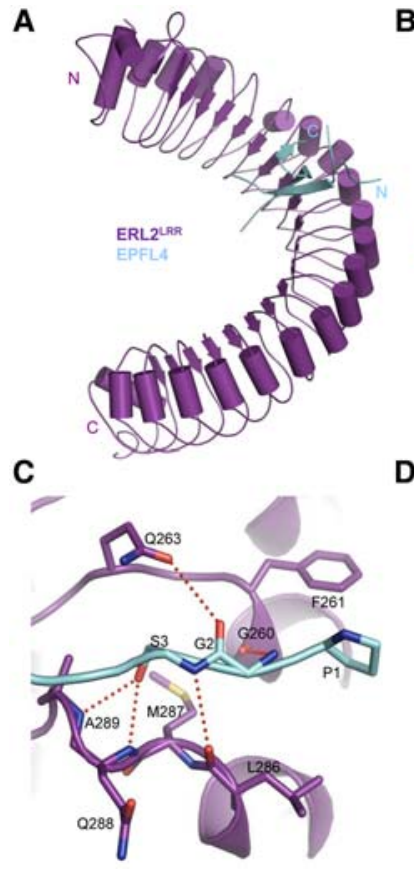

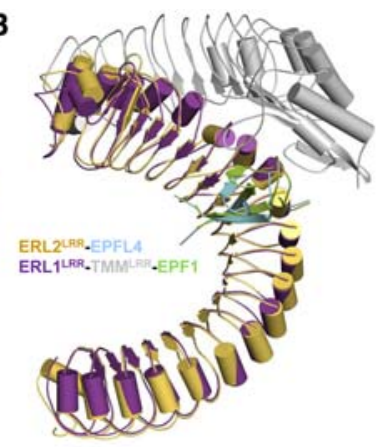

D

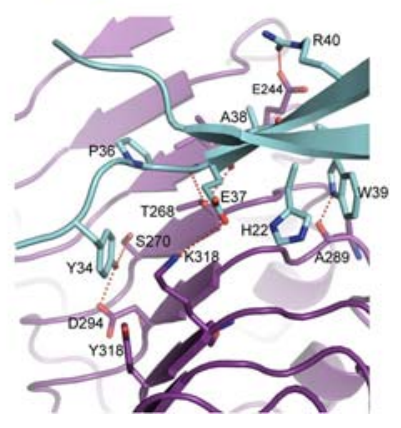

Figure 7. Recognition mechanism of EPFL4 by ERL2 ${ }^{\mathrm{LRR}} \cdot(A)$ Overall structure of EPFL4-ERL2 ${ }^{\text {LRR }}$. (N) N terminus; (C) C terminus. (B) Structural alignment of ERL2 ${ }^{\text {LRR }}$-EPFL4 and EPF1ERL1 ${ }^{\text {LRR }}-$ TMM $^{\mathrm{LRR}}$ complexes. The structure of ERL1 ${ }^{\mathrm{LRR}}$ was used as the template for the alignment. $(C)$ Detailed interactions of the N-terminal side of EPFL4 with ERL2 ${ }^{\text {LRR }}$. $(D)$ Detailed interactions of the central region of EPFL4 with ERL2 ${ }^{\text {LRR }}$.

compensated by the two EPFLs, which are recognized by ERfs without TMM, thus maintaining negative regulation of stomatal development. Many RLPs are present in plants (Gust and Felix 2014), and it will be intriguing to investigate whether other RLPs can use TMM-like mechanisms for ligand discrimination.

Binding of EPFs did not induce homodimerization of ERfs in either the presence or absence of TMM (Figs. 2B, 6B; Supplemental Fig. S5), suggesting that coreceptors are required for EPF-induced activation of ERfs. Indeed, a recent study demonstrated that the LRR-RK SERKs function as coreceptors with ERfs and TMM for the regulation of stomatal patterning (Meng et al. 2015). The structural mechanism of this remains unclear, but a clue to this can be gained from structural comparison between EPF1-ERL1 ${ }^{\text {LRR }}-\mathrm{TMM}^{\mathrm{LRR}}$ and other SERK-containing protein complexes. When the LRR-RK PXY (phloem intercalated with xylem) (Zhang et al. 2016) and ERL1 are aligned, EPF1 is located at a position similar to the peptide ligand TDIF bound by PXY ${ }^{\mathrm{LRR}}$ SERK2 ${ }^{\text {LRR }}$ (Supplemental Fig. S10). The hairpin loop of EPF1 is close to SERK2, suggesting that this region of EPF1 could be involved in the interaction with a SERK member or other partners to initiate ERf signaling. Interestingly, the hairpin loop region of the EPFL family members is much more variable as compared with the remaining parts (Supplemental Fig. S3B). Given the unequal redundancy of individual SERK members in stoma- tal patterning, this could be associated with the functional specificity of EPFL members (Meng et al. 2015). The positive regulation of stomatal development by EPFL9 can be explained by the possibility that its hairpin loop is unable to interact with a SERK member, although recruitment of a different partner by the loop remains formally possible. Consistently, EPF2 but not EPFL9 induced phosphorylation of downstream signaling components in plants (Lee et al. 2015). This possibility also agrees with the observation that substitution of this region of EPFL9 with that of EPF2 switched EPFL9 from positive to negative regulation of stomatal development (Ohki et al. 2011).

Negative regulation of stomata development in the stems of tmm knockout plants (Abrash and Bergmann 2010; Abrash et al. 2011) where EPF1,2 signaling is silenced suggests that the growth regulatory EPFL4,6 can potentiate the transduction of signals in the epidermis. On the other hand, although TMM is required for ERL1 recognition of EPF1, the structure of EPF1-ERL1 is similar to that of EPFL4-ERL2, in particular around the anti-parallel $\beta$ sheet of EPF1 and EPFL4, indicating that TMM binding has no impact on the relative orientation between ERL1 ${ }^{\text {LRR }}$ and EPF1. These results collectively suggest that EPF1-ERL1 and EPFL4-ERL2 may have shared coreceptors for signaling. In the future, it will be of interest to investigate whether SERK members have a role in signaling induced by EPFLs such as EPFL4,6.

The present study together with others demonstrates that TMM-ERf complexes and ERfs are the receptors of EPF1,2, EPFL9, and EPFL4,6, respectively (Abrash et al. 2011; Lee et al. 2012, 2015; Uchida et al. 2012). Our data also suggest possible ligand-receptor interactions between other EPFLs and ERfs. The "GS" motif is highly conserved among all of the EPFL members and is involved in the interaction with ERfs for both EPF1,2 and EPFL4. Given the conserved structures of the EPFL members as supported by modeling (Ohki et al. 2011) and structural studies, these data suggest that other EPFL members can also interact with ERfs. This possibility is supported by a recent study showing that EPFL2 interacts with ERfs for the regulation of leaf margin morphogenesis in Arabidopsis (Tameshige et al. 2016). Interestingly, in addition to the "GS" motif, the ERL2 ${ }^{\mathrm{LRR}}$-interacting residues of EPFL4,5,6 are also highly conserved in EPFL1,2,3,8 (Supplemental Fig. S3B). Furthermore, like EPFL4,5,6, EPFL1,2,3,8 have shorter C-terminal sides than EPF1,2, which interact with TMM ${ }^{\mathrm{LRR}}$ for the last two EPF peptides. These results suggest that EPFL1,2,3,8 might also interact with ERfs independent of TMM. Indeed, our biochemical assay showed that EPFL8 interacted with ERL1 $^{\text {LRR }}$ in the absence of TMM ${ }^{\text {LRR }}$ (Supplemental Fig. S11). This hypothesis is also in line with the observations that overexpression of EPFL1,2 has no obvious stomatal phenotypes in a wild-type background but displays noticeably reduced stomatal density in tmm, phenocopying that of EPFL4,5,6 (Abrash et al. 2011). In contrast, both the ERf- and TMM-interacting residues of EPF1,2 are conserved in EPFL7, suggesting that the interaction of this EPFL peptide with ERfs might require TMM. Further 
studies are needed to investigate whether the function of EPFL7 is TMM-dependent.

\section{Materials and methods}

Protein expression and purification

The extracellular LRR domains of ER (residues 24-580), ERL1 (residues 24-580), ERL2 (residues 28-580), TMM (residues 47-470), EPF1 (residues 53-104), EPF2 (residues 69-120), EPFL9 (residues 58-102), EPFL4 (residues 59-109), EPFL6 (residues 106-156), and EPFL8 (residues 46-99) were cloned into modified pFastBac vectors containing an $\mathrm{N}$-terminal hemolin $(\mathrm{Hem})$ signal peptide or a cleavable $\mathrm{N}$-terminal 6xHis-SUMO tag (Hem SUMO) with or without a C-terminal 6xHis tag (3HT or 3T, respectively). All of the proteins were expressed using the Bac-to-Bac baculovirus expression system (Invitrogen) protocols in High Five cells at $22^{\circ} \mathrm{C}$. High Five cells were grown in ESF 921 medium (Expression Systems) by shaking at $120 \mathrm{rpm}$ at $28^{\circ} \mathrm{C}$ until the density reached $2 \times 10^{6}$ cells per milliliter. One liter of cells $\left(2.0 \times 10^{6}\right.$ cells per milliliter) was infected with $20 \mathrm{~mL}$ of recombinant baculovirus. For purification of ERf ${ }^{\mathrm{LRR}}-\mathrm{TMM}{ }^{\mathrm{LRR}}$, baculoviruses of ERf and TMM were added at the same time. The supernatant was harvested via centrifugation after $60 \mathrm{~h}$ of infection. The supernatant was flowed through Ni-NTA (Novagen). Bound proteins were eluted by buffer containing $25 \mathrm{mM}$ Tris (pH 8.0), $150 \mathrm{mM} \mathrm{NaCl}$, and $250 \mathrm{mM}$ imidazole and further purified by size exclusion chromatography (Hiload 16/60Superdex 200 prep grade, GE Healthcare) in a buffer containing $10 \mathrm{mM}$ Bis-Tris (pH 6.0) and $100 \mathrm{mM} \mathrm{NaCl}$. To obtain the ERf ${ }^{\mathrm{LRR}}-\mathrm{EPF} 4$ or ERf ${ }^{\mathrm{LRR}}-\mathrm{TMM}^{\mathrm{LRR}}$-EPF1/2 complexes, the purified ERf ${ }^{\mathrm{LRR}}$ or $\mathrm{ERf}^{\mathrm{LRR}}-\mathrm{TMM}^{\mathrm{LRR}}$ and EPF proteins were mixed and incubated for $30 \mathrm{~min}$ at $4^{\circ} \mathrm{C}$. The mixture was subsequently subjected to gel filtration (Hiload 16/60, Superdex 200 prep grade, GE Healthcare) in a buffer containing $10 \mathrm{mM}$ Bis-Tris ( $\mathrm{pH}$ 6.0) and $100 \mathrm{mM} \mathrm{NaCl}$. Fractions corresponding to the complex were pooled together and subjected to ultrafiltration to $\sim 10 \mathrm{mg} / \mathrm{mL}$ for crystallization.

Crystallization, data collection, structure determination, and refinement

Crystallization experiments were performed by hanging drop vapor diffusion methods by mixing $1.0 \mu \mathrm{L}$ of protein with $1.0 \mu \mathrm{L}$ of reservoir solution at $18^{\circ} \mathrm{C}$. Diffraction-quality crystals of ERL1 ${ }^{\text {LRR }}-\mathrm{TMM}^{\mathrm{LRR}}$ were obtained in the buffer containing $4 \%(\mathrm{v} / \mathrm{v})$ tacsimate $(\mathrm{pH} 6.0)$ and $10 \%(\mathrm{w} / \mathrm{v})$ polyethylene glycol 3350. Good-quality crystals of ERL1 ${ }^{\text {LRR }}-$ TMM $^{\text {LRR }}-E P F 1$ and ERL1 ${ }^{\text {LRR }}-$ TMM $^{\text {LRR }}$-EPF2 were obtained in the buffer containing $0.1 \mathrm{mM}$ ammonium citrate tribasic ( $\mathrm{pH} 7.0)$ and $10 \%$ polyethylene glycol 3350. For ERL2-EPF4, high-quality crystals emerged in the buffer containing 0.1 M MES monohydrate ( $\mathrm{pH} 6.5)$ and $12 \%$ polyethylene glycol 20000. All of the crystals were flash-frozen using the reservoir buffer plus $15 \%$ glycerol as the cryoprotectant. All of the diffraction data sets were collected at the Shanghai Synchrotron Radiation Facility (SSRF) on beam line BL17U1. All of the data were processed using the HKL2000 software package (Otwinowski and Minor 1997). The crystal structure of ERL1 ${ }^{\text {LRR }}$-TMM ${ }^{\text {LRR }}$ was determined by molecular replacement (MR) with PHASER (McCoy et al. 2007) using the structure of FLS2 (Protein Data Bank: 4MN8) as the initial searching model. The model from MR was built with the program Coot (Emsley and Cowtan 2004) and subsequently subjected to refinement by the program PHENIX (Adams et al. 2002). The other crystal structures were determined by MR using the structure of ERL $1^{\mathrm{LRR}}$ $\mathrm{TMM}^{\mathrm{LRR}}$ or ERL1 ${ }^{\mathrm{LRR}}$ as the initial searching model. The final refinement statistics are summarized in Supplemental Table 1. Structural figures were drawn using the program PyMOL (http://www.pymol.org).

ITC

The binding affinities of ERL1 $1^{\mathrm{LRR}}$ and ERL1 $1^{\mathrm{LRR}}-\mathrm{TMM}^{\mathrm{LRR}}$ with EPFs were measured using ITC200 (Microcal LLC) at $25^{\circ} \mathrm{C}$ in a buffer containing $10 \mathrm{mM}$ Bis-Tris (pH 6.0) and $100 \mathrm{mM} \mathrm{NaCl}$. Approximately $0.3 \mathrm{mM}$ EPF peptides was injected into the stirred calorimeter cell $(250 \mu \mathrm{L})$ containing $0.03 \mathrm{mM} \mathrm{ERL1}{ }^{\mathrm{LRR}}$ or ERL1 $^{\text {LRR }}-$ TMM $^{\text {LRR }}$ with $24 \times 1.5 \mu \mathrm{L}$ at 150 -sec intervals. The stirring speed was $750 \mathrm{rpm}$. The heat of dilution generated by the titration of peptides into the buffer was subtracted. Measurements of the binding affinity of all of the titration data were analyzed using Origin software (MicroCal Software).

\section{Pull-down assay}

The purified 6xHis-tagged ERf $\mathrm{fRR}^{\mathrm{LR}}$ protein with excess EPFs was mixed and incubated with $40 \mu \mathrm{L}$ of $\mathrm{Ni}^{+}$resin for $30 \mathrm{~min}$ on ice. The resin was washed four times with $1 \mathrm{~mL}$ of washing buffer containing $25 \mathrm{mM}$ Tris (pH 8.0), $250 \mathrm{mM} \mathrm{NaCl}$, and $15 \mathrm{mM}$ imidazole. All of the resins were added with $100 \mu \mathrm{L}$ of SDS loading buffer and heated for $5 \mathrm{~min}$ to $100^{\circ} \mathrm{C}$. Next, the supernatants containing bound proteins were separated by SDS-PAGE, and proteins were detected by Coomassie blue staining. Similar procedures were used to test the interaction of ERL1 ${ }^{\mathrm{LRR}}$ TMM $^{\mathrm{LRR}}$ with various $6 \mathrm{xHis-tagged} \mathrm{EPF1} \mathrm{mutants.}$

\section{Ligand competition assays}

The ER ${ }^{\text {LRR }}-\mathrm{TMM}^{\mathrm{LRR}}$ or ERL1 ${ }^{\mathrm{LRR}}-\mathrm{TMM}^{\mathrm{LRR}}$ complex was mixed and incubated with $10 \mu \mathrm{M}$ EPF2-6xHis or EPF1-6xHis peptides in the presence or absence of different concentrations of bioactive EPFL9 peptide for $1 \mathrm{~h}$ at $4^{\circ} \mathrm{C}$ with gentle agitation. The reaction mixture was then flowed through $\mathrm{Ni}^{+}$beads and washed four times with $1 \mathrm{~mL}$ of wash buffer to separate the bound and free $\mathrm{ER}^{\mathrm{LRR}}-\mathrm{TM} \mathrm{M}^{\mathrm{LRR}}$ or ERL1 ${ }^{\mathrm{LRR}}-\mathrm{TMM}^{\mathrm{LRR}}$. Bound proteins were eluted by elution buffer, added to SDS loading buffer for $5 \mathrm{~min}$ at $100^{\circ} \mathrm{C}$, and detected on SDS-PAGE gel by Coomassie blue staining.

\section{Gel filtration assay}

The ERf ${ }^{\mathrm{LRR}}$, ERf $\mathrm{ER}^{\mathrm{LRR}}-\mathrm{TMM}^{\mathrm{LRR}}$, and EPFs proteins, purified as described above, were mixed and incubated for $30 \mathrm{~min}$ at $4^{\circ} \mathrm{C}$ before being subjected to gel filtration analysis (Hiload 16/60 Superdex 200 prep grade, GE Healthcare) in a buffer containing $10 \mathrm{mM}$ Bis-Tris (pH 6.0) and $100 \mathrm{mM} \mathrm{NaCl}$. Samples from relevant fractions were applied to SDS-PAGE and visualized by Coomassie blue staining.

\section{Plant materials and growth conditions}

The Arabidopsis thaliana ecotype Columbia was used as the wild type. Tmm-1 (CS6140) was acquired from the Arabidopsis Biological Resource Center (Ohio State University). Seedlings were grown on modified Murashige and Skoog medium plates supplemented with $1 \%(\mathrm{w} / \mathrm{v})$ sucrose. Plants were grown in a soil mixture with a 1:1 ratio of Promix PGX (Premier Horticulture, Inc.) and vermiculite (Pametto Vermiculite Co.) 
supplemented with Miracle-Gro (Scotts) and $\sim 3.5 \mathrm{mg} / \mathrm{cm}^{3}$ Osmocoat $15-9-12$ (Scotts) at $20^{\circ} \mathrm{C}$ under long-day conditions (18 h light/6 h dark).

\section{Plasmid construction and plant transformation}

To construct a plasmid carrying proTMM:TMM-3XHA $(\mathrm{pESH}$ 730 ), the TMM coding region was cloned behind the 540-basepair TMM promoter sequence and in-frame with $3 \times$ hemagglutinin (HA) tag (YPYDVPDYAGAYPYDVPDYAQLYPYDVPDYA) into the pZP222 vector. A 35S terminator was placed after the stop codon of 3xHA. The L281D and E379R substitutions were introduced into TMM by overlap extension PCR using pESH730 as a template. The amplified fragment was digested with RsrII and PstI, inserted into pESH 730, and sequenced. The plasmids carrying proTMM:TMM(L281D)-3XHA and proTMM:TMM(E379R)-3XHA sequences were named pESH 731 and pESH 732, respectively. The described plasmids were introduced into an Agrobacterium tumefaciens strain (GV3101/ pMP90) by electroporation and into tmm-1 mutants by the floral dip method (Clough and Bent 1998). The transgenic plants were selected on Murashige and Skoog medium plates containing gentamicin.

\section{Differential interference contrast (DIC) microscopy}

Samples were fixed overnight with ethanol:acetic acid (9:1 [v/v]). After fixation, samples were rehydrated with an ethanol series to $30 \%(\mathrm{v} / \mathrm{v})$ ethanol and cleared in chloral hydrate solution (chloral hydrate:water:glycerol, 8:1:1 [w/v/v]). Microscopic observations were performed using a Nikon Eclipse 80i microscope with DIC optics; images were obtained with a 12-megapixel cooled color DXM-1200c (Nikon) camera. The stomatal index was calculated using the formula (number of stomata/total number of epidermal cells) $\times 100$. The stomatal clustering fraction was calculated using the formula number of clustered stomata/total number of stomata.

\section{EPF1 bioassay}

Wild-type Arabidopsis seeds were germinated on modified Murashige and Skoog medium plates supplemented with $1 \times$ Gamborg B5 vitamins and $1 \%(\mathrm{w} / \mathrm{v})$ sucrose. One day after germination, the seedlings were transferred to a liquid MS-0 medium containing $1 \%(\mathrm{w} / \mathrm{v})$ sucrose, $40 \mathrm{mg} / \mathrm{mL}$ timentin, and $10 \mathrm{mM}$ EPF 1 or EPF1 with substitutions. After $5 \mathrm{~d}$ of incubation at $20^{\circ} \mathrm{C}$ under long-day conditions (18 h light/6 h dark), the stomatal index was measured on the abaxial side of cotyledons by DIC microscopy. For microscopy, seedlings were fixed overnight in ethanol:acetic acid (9:1), rehydrated with an ethanol series to $50 \%(\mathrm{v} / \mathrm{v})$ ethanol, and then cleared in a mixture of $8: 1: 1$ chloral hydrate:water:glycerol.

\section{Acknowledgments}

We thank S. Huang and J. He at the Shanghai Synchrotron Radiation Facility (SSRF) for assistance with data collection. We thank Dr. Heqiao Zhang and Dr. Zhen Wu for assistance with data collection and ITC assays. This research was funded by Projects of International Cooperation and Exchanges National Natural Science Foundation of China (31420103906), the Chinese Ministry of Science and Technology (2015CB910200), and the National Natural Science Foundation of China
(31421001) to J.C., and the National Science Foundation (IOS0843340) to E.D.S.

\section{References}

Abrash EB, Bergmann DC. 2010. Regional specification of stomatal production by the putative ligand CHALLAH. Development 137: 447-455.

Abrash EB, Davies KA, Bergmann DC. 2011. Generation of signaling specificity in Arabidopsis by spatially restricted buffering of ligand-receptor interactions. Plant Cell 23: 2864-2879.

Adams PD, Grosse-Kunstleve RW, Hung LW, Ioerger TR, McCoy AJ, Moriarty NW, Read RJ, Sacchettini JC, Sauter NK, Terwilliger TC. 2002. PHENIX: building new software for automated crystallographic structure determination. Acta Crystallogr D Biol Crystallogr 58: 1948-1954.

Caine RS, Chater CC, Kamisugi Y, Cuming AC, Beerling DJ, Gray JE, Fleming AJ. 2016. An ancestral stomatal patterning module revealed in the non-vascular land plant Physcomitrella patens. Development 143: 3306-3314.

Clough SI, Bent AF. 1998. Floral dip: a simplified method for Agrobacterium-mediated transformation of Arabidopsis thaliana. Plant J 16: 735-743.

De Smet I, Voss U, Jurgens G, Beeckman T. 2009. Receptor-like kinases shape the plant. Nat Cell Biol 11: 1166-1173.

Emsley P, Cowtan K. 2004. Coot: model-building tools for molecular graphics. Acta Crystallogr D Biol Crystallogr 60: 2126-2132.

Geisler M, Yang M, Sack FD. 1998. Divergent regulation of stomatal initiation and patterning in organ and suborgan regions of the Arabidopsis mutants too many mouths and four lips. Planta 205: 522-530.

Geisler M, Nadeau J, Sack FD. 2000. Oriented asymmetric divisions that generate the stomatal spacing pattern in Arabidopsis are disrupted by the too many mouths mutation. Plant Cell 12: $2075-2086$.

Gust AA, Felix G. 2014. Receptor like proteins associate with SOBIR1-type of adaptors to form bimolecular receptor kinases. Curr Opin Plant Biol 21: 104-111.

Hara K, Kajita R, Torii KU, Bergmann DC, Kakimoto T. 2007. The secretory peptide gene EPF1 enforces the stomatal one-cellspacing rule. Genes Dev 21: 1720-1725.

Hara K, Yokoo T, Kajita R, Onishi T, Yahata S, Peterson KM, Torii KU, Kakimoto T. 2009. Epidermal cell density is autoregulated via a secretory peptide, EPIDERMAL PATTERNING FACTOR 2 in Arabidopsis leaves. Plant Cell Physiol 50: 1019-1031.

Hunt L, Gray JE. 2009. The signaling peptide EPF2 controls asymmetric cell divisions during stomatal development. Curr Biol 19: 864-869.

Hunt L, Bailey KJ, Gray JE. 2010. The signalling peptide EPFL9 is a positive regulator of stomatal development. New Phytol 186: 609-614.

Kondo T, Kajita R, Miyazaki A, Hokoyama M, Nakamura-Miura T, Mizuno S, Masuda Y, Irie K, Tanaka Y, Takada S, et al. 2010. Stomatal density is controlled by a mesophyll-derived signaling molecule. Plant Cell Physiol 51: 1-8.

Lee JS, Kuroha T, Hnilova M, Khatayevich D, Kanaoka MM, McAbee JM, Sarikaya M, Tamerler C, Torii KU. 2012. Direct interaction of ligand-receptor pairs specifying stomatal patterning. Genes Dev 26: 126-136.

Lee JS, Hnilova M, Maes M, Lin YC, Putarjunan A, Han SK, Avila J, Torii KU. 2015. Competitive binding of antagonistic peptides fine-tunes stomatal patterning. Nature 522: 439-443. 
MacDonald BT, Tamai K, He X. 2009. Wnt/ $\beta$-catenin signaling: components, mechanisms, and diseases. Dev Cell 17: 9-26.

McCoy AJ, Grosse-Kunstleve RW, Adams PD, Winn MD, Storoni LC, Read RJ. 2007. Phaser crystallographic software. I Appl Crystallogr 40: 658-674.

Meng X, Chen X, Mang H, Liu C, Yu X, Gao X, Torii KU, He P, Shan L. 2015. Differential function of Arabidopsis SERK family receptor-like kinases in stomatal patterning. Curr Biol 25: 2361-2372.

Motomitsu A, Sawa S, Ishida T. 2015. Plant peptide hormone signalling. Essays Biochem 58: 115-131.

Nadeau JA, Sack FD. 2002. Control of stomatal distribution on the Arabidopsis leaf surface. Science 296: 1697-1700.

Ohki S, Takeuchi M, Mori M. 2011. The NMR structure of stomagen reveals the basis of stomatal density regulation by plant peptide hormones. Nat Commun 2: 512.

Olsen JL, Rouze P, Verhelst B, Lin YC, Bayer T, Collen J, Dattolo E, De Paoli E, Dittami S, Maumus F, et al. 2016. The genome of the seagrass Zostera marina reveals angiosperm adaptation to the sea. Nature 530: 331-335.

Otwinowski Z, Minor W. 1997. Processing of X-ray diffraction data collected in oscillation mode. Methods Enzymol 276: 307-326.

Shpak ED. 2013. Diverse roles of ERECTA family genes in plant development. J Integr Plant Biol 55: 1238-1250.
Shpak ED, McAbee JM, Pillitteri LJ, Torii KU. 2005. Stomatal patterning and differentiation by synergistic interactions of receptor kinases. Science 309: 290-293.

Song W, Han Z, Wang J, Lin G, Chai J. 2016. Structural insights into ligand recognition and activation of plant receptor kinases. Curr Opin Struct Biol 43: 18-27.

Sugano SS, Shimada T, Imai Y, Okawa K, Tamai A, Mori M, HaraNishimura I. 2010. Stomagen positively regulates stomatal density in Arabidopsis. Nature 463: 241-244.

Tameshige T, Okamoto S, Lee JS, Aida M, Tasaka M, Torii KU, Uchida N. 2016. A secreted peptide and its receptors shape the auxin response pattern and leaf margin morphogenesis. Curr Biol 26: 2478-2485.

Torii KU, Mitsukawa N, Oosumi T, Matsuura Y, Yokoyama R, Whittier RF, Komeda Y. 1996. The Arabidopsis ERECTA gene encodes a putative receptor protein kinase with extracellular leucine-rich repeats. Plant Cell 8: 735-746.

Uchida N, Lee JS, Horst RJ, Lai HH, Kajita R, Kakimoto T, Tasaka M, Torii KU. 2012. Regulation of inflorescence architecture by intertissue layer ligand-receptor communication between endodermis and phloem. Proc Natl Acad Sci 109: 6337-6342.

Yang M, Sack FD. 1995. The too many mouths and four lips mutations affect stomatal production in Arabidopsis. Plant Cell 7: 2227-2239.

Zhang H, Lin X, Han Z, Wang I, Qu LJ, Chai J. 2016. SERK family receptor-like kinases function as co-receptors with PXY for plant vascular development. Mol Plant 9: 1406-1414. 


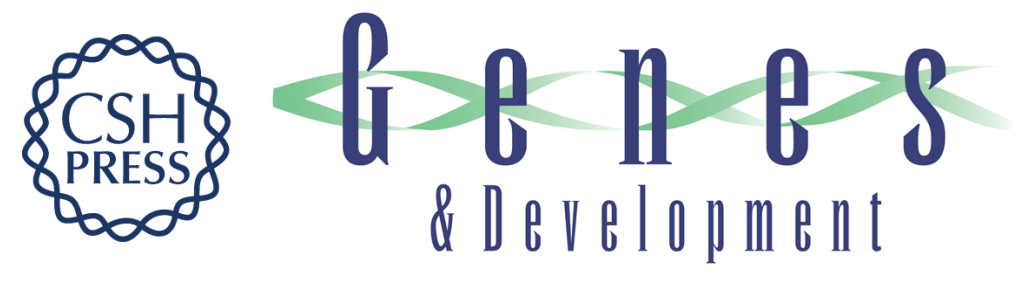

\section{A receptor-like protein acts as a specificity switch for the regulation of stomatal development}

Guangzhong Lin, Liang Zhang, Zhifu Han, et al.

Genes Dev. 2017, 31: originally published online May 23, 2017

Access the most recent version at doi:10.1101/gad.297580.117

\section{Supplemental http://genesdev.cshlp.org/content/suppl/2017/05/23/gad.297580.117.DC1 Material}

References This article cites 34 articles, 12 of which can be accessed free at: http://genesdev.cshlp.org/content/31/9/927.full.html\#ref-list-1

Creative This article is distributed exclusively by Cold Spring Harbor Laboratory Press for the first Commons six months after the full-issue publication date (see

License http://genesdev.cshlp.org/site/misc/terms.xhtml). After six months, it is available under a Creative Commons License (Attribution-NonCommercial 4.0 International), as described at http://creativecommons.org/licenses/by-nc/4.0/.

Email Alerting Receive free email alerts when new articles cite this article - sign up in the box at the top Service right corner of the article or click here.

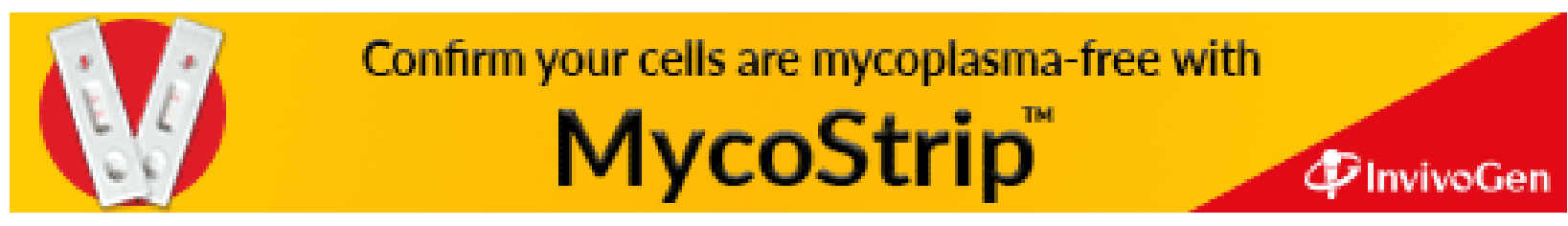

